\title{
UX DESIGNER: QUEM É ESTE PROFISSIONAL E QUAL É A SUA FORMAÇÃO E COMPETÊNCIAS?
}

\author{
UX DESIGNER: WHO IS THIS PROFESSIONAL AND WHAT IS HIS \\ FORMAL EDUCATION AND SKILLS?
}

Manuela Quaresma

\begin{abstract}
Este artigo busca discutir o que é o trabalho em UX, quais são as disciplinas relacionadas e qual é o papel do designer nesse contexto. Primeiramente, são explicitados os conceitos e as definições de Interação HumanoComputador (IHC), Usabilidade e Experiência do Usuário (UX) a partir de uma perspectiva histórica. A partir de então, as disciplinas relacionadas a UX são descritas a fim de se observar o valor do design na experiência do usuário e como é o envolvimento do designer no processo de desenvolvimento de um sistema interativo digital, com foco no Design Centrado no Usuário. Também são discutidos dados do mercado internacional a respeito da área e quais são as características dos profissionais envolvidos, que apresentam formações e atuações bem diversas de modo geral. Considera-se que o designer na área UX tem uma função estratégica no processo.
\end{abstract}

Palavras chave: Interação humano-computador (IHC), usabilidade, experiência do usuário (UX), mercado de trabalho

This article discusses what the work in UX is, what are the related disciplines and what is the role of the designer in this context. First, the concepts and definitions of Human-Computer Interaction (HCI), Usability and User Experience (UX) are explained from a historical perspective. From then on, UX-related disciplines are described in order to observe the value of design in the user experience and how is the designer's involvement in the process of developing a digital interactive system, focusing on User-Centered Design. Also, it is discussed data of UX international market and what are the characteristics of the professionals involved, that present very different education and performances in general. It is considered that the designer in the UX area has a strategic function in the process.

Keywords: human-computer interaction (HCI), usability, user experience (UX), labor marke 


\section{IHC, Usabilidade e UX}

Hoje em dia, as oportunidades de quem trabalha com tecnologia e sistemas interativos são cada vez maiores. Novas tecnologias vêm surgindo e, como será a interação dos usuários com elas é um dos grandes desafios do designer e de todos aqueles envolvidos no projeto dessas interações. Se antes os usuários estavam interessados na quantidade de funcionalidades que o sistema poderia lhes proporcionar, hoje, estão mais preocupados em como o sistema fará parte de suas vidas, de modo que não seja só satisfatório, mas que ele lhes proporcione encantamento e uma ótima experiência de uso em todos os momentos de interação.

$\mathrm{Na}$ evolução da interação com tecnologias e nos primórdios do que se concluiu como a área de interação humano-computador (IHC), começamos a interagir com os primeiros computadores ainda muito complicados e complexos, passando para computadores menores e mais simples, os PCs, depois para os computadores portáteis e, atualmente, lidamos com uma variedade extensa de sistemas interativos - notebooks, smartphones, tablets, smartwatches, etc. Durante esse processo, as interfaces dessa comunicação humanomáquina mudaram bastante. Quando no início era uma grande novidade e as pessoas estavam interessadas no que aquela tecnologia poderia trazer para ela, agora, ela já faz parte do cotidiano de muitas pessoas e não se tolera mais interfaces mal concebidas, principalmente, em questões de utilidade e experiência de uso.

A Interação Humano-Computador (IHC) começou a ser tratada como área do conhecimento por volta da década de 1970, e tem suas origens na Ergonomia/Fatores Humanos, na Psicologia Cognitiva, no Design e, obviamente, na Ciência da Computação (figura 1). De início, eram tratadas questões relacionadas a interação com hardware (terminais de vídeo CRT e teclado), treinamento, documentação (manuais), editores de texto, etc, (HARTSON E PYLA, 2012) e, depois, o foco passa a ser muito mais a interação com os softwares em geral.

Antes da consolidação do termo IHC, a área chegou a ser chamada de "human factors in computers" (fatores humanos em computadores), no que se referia a interação com hardwares, e de "human factors in software engineering" (fatores humanos em engenharia de software), numa abordagem mais voltada para a interação com os softwares. Entretanto, não há como separar uma abordagem da outra, pois onde há software há sempre um suporte de hardware (pelo menos até hoje em dia!), e sua relação com a Ergonomia (human factors), que é extremamente forte, se dá, principalmente, no que concerne aos métodos de pesquisa e análise utilizados em projetos de interface, como a Análise da Tarefa.

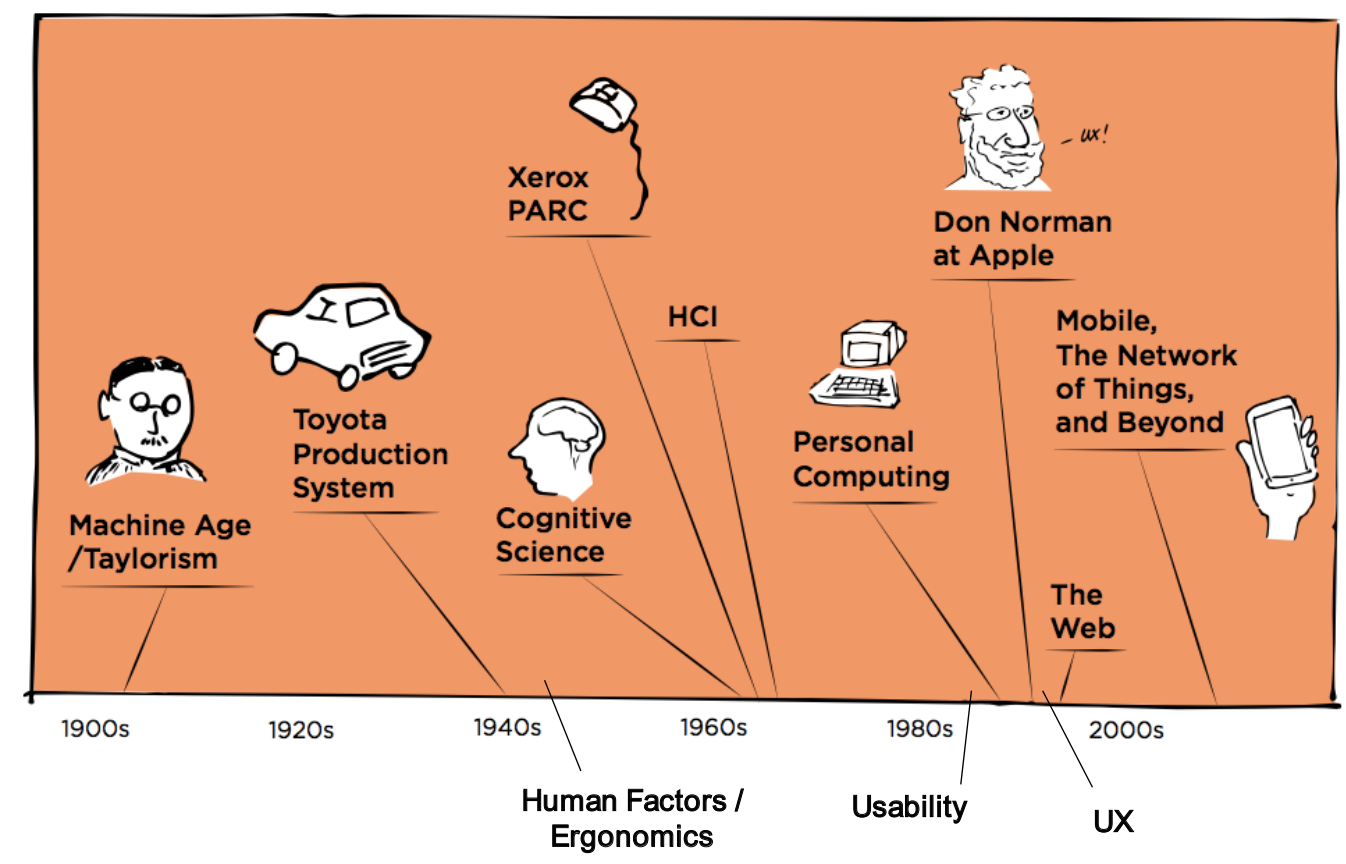

Figura 1: a história relacionada a experiência do usuário desde o taylorismo até os dias de hoje. Fonte: Buley (2013) com informações adicionais inseridas pela autora. 
1 https://www.nngroup. com/articles/tenusability-heuristics/ epequenas ou grandes resoluções).
Com as diversas pesquisas que vinham sendo realizadas na área de IHC, a partir do início dos anos 1980, junto com a popularização dos computadores pessoais (PC) e a forte influência da Psicologia Cognitiva, surge o que conhecemos hoje como 'Usabilidade' (que de início foi chamada de "software psychology" por Shneiderman, 1980). A compreensão do comportamento e desempenho humano na interação, considerando a cognição, memória (curto e longo prazo), percepção, atenção e tomada de decisão passam a ser fundamentais para o desenvolvimento de soluções adequadas na comunicação entre o humano e o computador.

Uma das mais divulgadas definições de 'usabilidade' é a da International Organization for Standardization - ISO 9241-11 (1998), que a define como "a medida na qual um produto pode ser usado por usuários específicos para alcançar objetivos específicos com eficácia, eficiência e satisfação em um contexto específico de uso". Assim, após diversas tentativas de definição para o termo usabilidade (BRANGIER E BARCENILLA, 2003), chega-se a especificação bastante reconhecida dos três componentes (medidas) mais importantes da usabilidade - eficácia, eficiência e satisfação, sendo os dois primeiros medidos de forma objetiva e o terceiro de maneira mais subjetiva, mas ainda assim sendo um resultado de um alcance bem-sucedido das duas primeiras medidas.

Enquanto os componentes da usabilidade vinham sendo estabelecidos, pesquisadores da área de IHC trabalhavam e pesquisavam as questões da interação do humano com o computador, através da interface, com base nas teorias e premissas da Psicologia Cognitiva. Os resultados dessas pesquisas levaram ao que se conhece muito bem na área como princípios, critérios e heurísticas de usabilidade, de pesquisadores renomados como Shneiderman (1987), Norman (1988), Bastien e Scapin (1993) e Nielsen (1994), sendo este último um dos mais conhecidos pelas suas 10 heurísticas de usabilidade ${ }^{\mathbf{1}}$. Até hoje todos esses princípios são bastante utilizados no design de interfaces e design de interação e são base para diversos métodos de análise, avaliação e concepção de interfaces, assim como são utilizados para fundamentar diretrizes para tecnologias e interações específicas para contextos específicos - como a interação humano-robô e humano-automóvel.

Entretanto, no final da década de 1990 e início dos anos 2000, novos componentes da interação além das medidas de usabilidade começam a ser questionados, como prazer, emoção, afetividade, encantamento, etc., na interação. Uma vez que a medida de satisfação da usabilidade se limita ao resultado satisfatório da relação eficácia e eficiência do sistema, quais outros componentes fazem parte da experiência da interação com o sistema? Os usuários já sabem reconhecer uma interface/produto com boa usabilidade e se acostumaram com isso, pois passa a ser o mínimo que se espera. Jordan (2002) faz, nesse sentido, uma comparação com a hierarquia das necessidades humanas de Maslow (MASLOW, 1970 apud JORDAN, 2002 - figura 2) no que ele chama de 'nova ergonomia' (ou 'novo fatores humanos), enfatizando que as pessoas querem mais do que usabilidade na interação, elas querem ter prazer nessa interação.
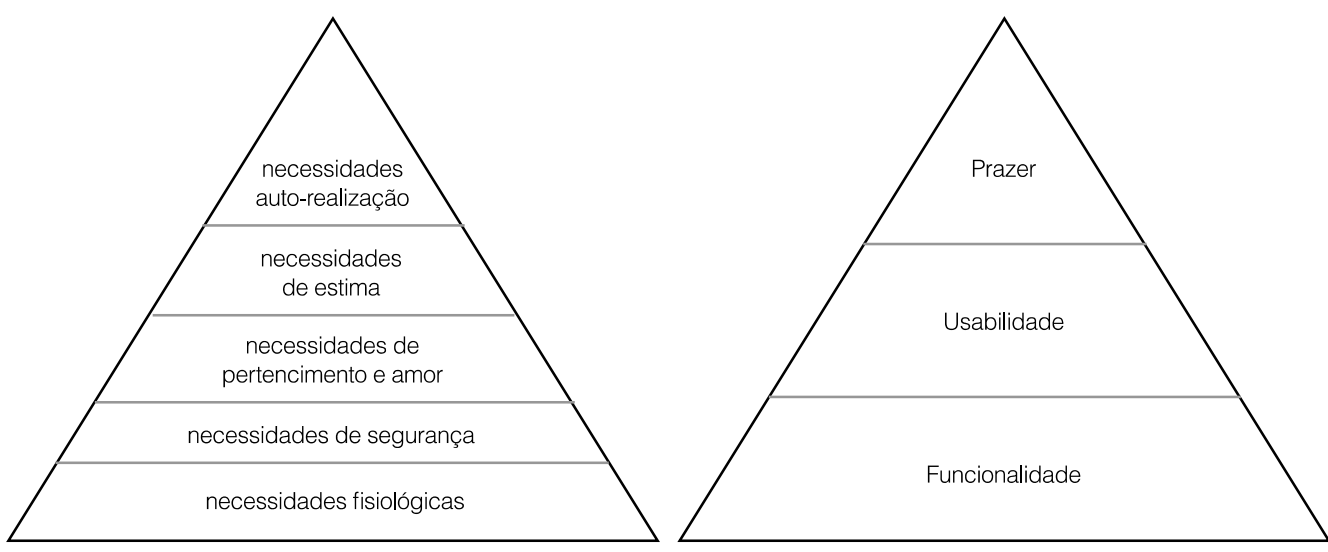

Figura 2: hierarquia de necessidades humanas de Maslow e hierarquia da nova Ergonomia de Jordan. Fonte: Jordan (2002) [tradução da autora]

A partir de então, a usabilidade passa a ser um requisito básico numa interface e numa interação. Agora, é preciso motivar o usuário a "comprar" a ideia da interação e uso do produto, é preciso encantar e propor- cionar uma excelente experiência ao longo do uso e tentar mantê-lo utilizando o produto pelo máximo de tempo possível. Todos esses fatores levaram ao conceito conhecido como User Experience (ou UX 
ou experiência do usuário). Entretanto, boa parte desta experiência ainda é resultado de um bom projeto que segue à risca os princípios de usabilidade, e este continua a ser um ponto de partida para uma boa experiência.

O termo user experience (UX) foi primeiramente utilizado por Donald Norman quando ele trabalhava para a Apple no início dos anos de 1990 e denominou seu grupo de trabalho como "the User Experience Architect's Office” (NORMAN, 2013). Neste momento, Norman se referia ao termo como um conceito de algo amplo que abrangia toda uma experiência que uma pessoa poderia ter ao interagir com um produto qualquer e não necessariamente digital, apesar de estar na Apple. O conceito definido por Norman se relaciona a todas as situações em que o usuário está envolvido com o produto, seja interagindo com o produto, seja pensando nele.

De maneira objetiva, Kuniavsky (2010) conceitua muito bem a experiência do usuário como:

“a totalidade das percepções dos usuários finais enquanto interagem com um produto ou serviço. Essas percepções incluem eficácia (quão bom é o resultado?), eficiência (o quão rápido ou barato é?), satisfação emocional (quão bom é?), e a qualidade da relação com a entidade que criou o produto ou o serviço (quais expectativas se criaram para as próximas interações?).” [tradução da autora]

Hartson e Pyla (2012) ampliam a definição da experiência do usuário como

\begin{abstract}
"a totalidade do efeito ou dos efeitos sentidos por um usuário como resultado da interação com, e o contexto de uso de, um sistema, um dispositivo ou um produto, incluindo a influência da usabilidade, da utilidade e do impacto emocional durante a interação, e desfrutando da memória após a interação. 'Interação com'é ampla e envolve a visão, o toque e o pensamento sobre o sistema ou produto, incluindo a admiração por ele e sua apresentação antes de qualquer interação fisica". [tradução da autora]
\end{abstract}

Em ambas as definições é possível perceber que, o que é dito como experiência de uso com um pro- duto vai além da interação imediata com a interface do produto. A experiência engloba todas as relações que se têm com o produto, desde o momento em que se observa ou se tem conhecimento de sua existência, passando pelo uso do produto propriamente dito, pelo pensamento sobre o produto, a sua manutenção até o momento em que se se desfaz dele. A experiência vai além da usabilidade do produto ou serviço. É importante atentar, também, que toda a estrutura da empresa ou instituição provedora do produto influencia na experiência, assim como todo o ecossistema organizacional a sua volta.

\section{Disciplinas relacionadas à UX}

Como trabalhar para a experiência do usuário requer a compreensão dos diversos pontos de contato entre o humano e o produto na IHC, é preciso compreender e dominar diversas disciplinas, tanto relacionadas ao Design quanto a outras áreas. Kuniavsky (2010) enumera uma série delas relacionadas ao projeto do produto e o serviço a sua volta, como: design de identidade, design de interface, design industrial (design de produto), design de interação, design de informação, design de serviço e a arquitetura de informação. Cada uma dessas disciplinas tem suas especificidades, mesmo fazendo parte de uma única, o Design, conforme descrito a seguir:

\section{Design de Identidade}

Esta disciplina do Design diz respeito a tudo que se relaciona com a identidade do produto, seja seu aspecto formal de como ele se parece, que associações ele evoca e quais são suas principais características. Quando se trabalha a identidade do produto, o projeto não está restrito a apenas aos aspectos estéticos do produto em si, mas tudo que está a ele relacionado, como a comunicação do produto, os pontos de vendas, a própria marca e todos os aspectos que podem remeter ao produto na sua identidade.

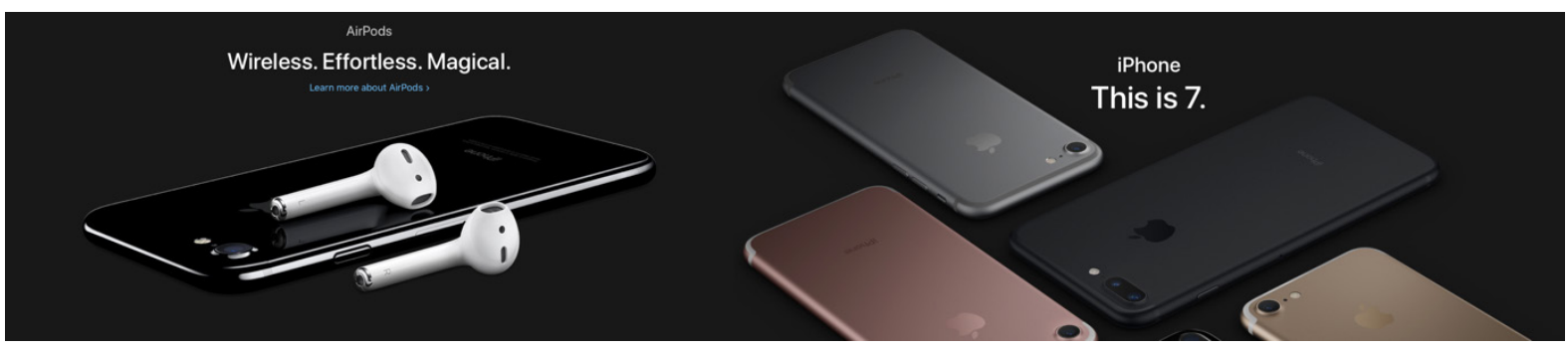

Figura 3: Os produtos da Apple são um bom exemplo de uma aplicação alinhada de Design de Identidade. É possível observar que os produtos mantêm uma mesma identidade, de aspecto clean com predominância das cores preta e branca, tanto na sua linha de produtos físicos quanto nas interfaces digitais. Fonte: http://www.apple.com 


\section{Design de Interface [digital]}

Nesta disciplina do projeto o foco está na interface do produto em si, onde o usuário interage diretamente. Interface de um sistema interativo digital pode ser as telas de um website, de um aplicativo de smartphone ou smartwatch, onde elementos de interação, ícones, botões, textos estarão dispostos de maneira organizada para que durante a interação um usuário possa se guiar desempenhando tarefas até alcançar o seu objetivo. É neste momento que as questões de usabilidade serão trabalhadas como muito mais intensidade, sempre considerando os princípios relacionados (como feedback, condução, significados e códigos, etc.), as tarefas (e suas atividades) a serem desempenhadas e o contexto de uso. Cada elemento de interação da interface deve estar ali para atender uma determinada necessidade, levando-se em conta que todos os elementos fazem parte de um todo e que devem se comunicar de maneira fluida e consistente.
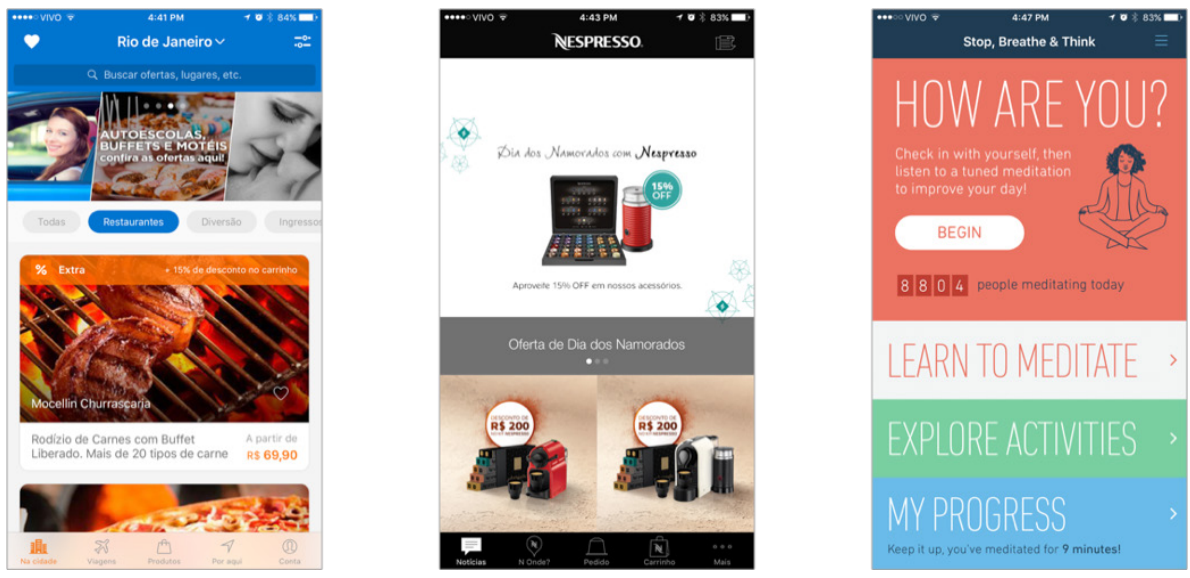

Figura 4: Essas telas de aplicativos (Peixe Urbano, Nespresso e Breathe) demostram exemplos de aplicação do Design de Interface. Fonte: autora

\section{Design Industrial (ou Design de Produ- to $^{2}$ )}

Como dito anteriormente, onde há software há hardware, e nesta disciplina do Design são tratadas as questões relacionadas a parte da interação física com o produto, com o hardware. Muitos dos dispositivos que utilizamos não são concebidos apenas por telas; eles são objetos que interagimos associados ao software e que formam um todo. Eles têm peso, forma, cor, pega, volumes, etc., que precisam estar adequados para a interação com os inputs físicos do ser humano (na maior parte das vezes, pelos dedos e pelas mãos). Questões de ergonomia de hardware, como o clássico uso de dados antropométricos para a concepção do produto são os fatores principais nessa disciplina para melhor projeto do sistema interativo. Por exemplo, por mais que um smartphone seja constituído basicamente por uma tela sensível ao toque, ele [ainda] tem uma forma tridimensional com poucos botões de empurrar ou deslizar que fazem parte da interação. O tamanho, a forma e sensação dessa interação também tem suas questões que precisam ser trabalhadas com cuidado e que influenciam na experiência do usuário. refere a um produto

físico e não digital diferentemente do uso da mesma palavra no resto do texto. A ênfase aqui é na disciplina conhecida no Brasil como Design de Produto (antigo Desenho Industrial ou Industrial Design em inglês) epequenas ou grandes resoluções).

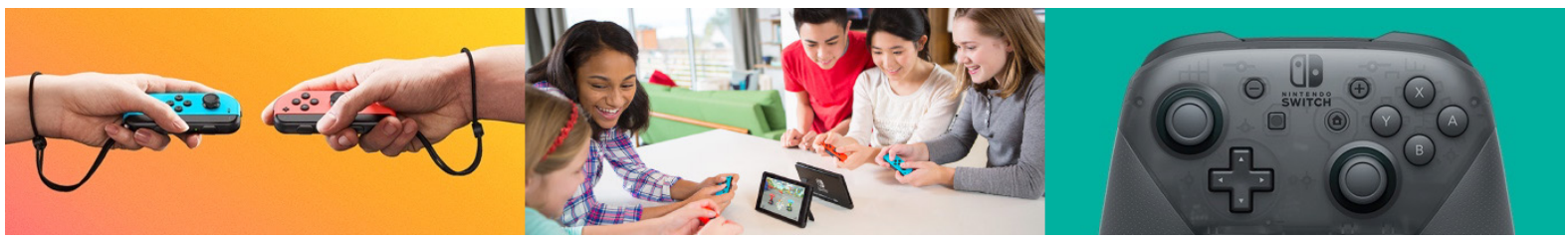

Figura 5: O dispositivo Nintendo Switch apresenta a combinação de interface digital e interface física no Design Industrial. Na tela digital estão as imagens do jogo e parte do corpo do dispositivo contém os controles físicos do jogo. Fonte: http://www.nintendo.com 


\section{Design de Interação}

Nesta disciplina, como o nome deixa claro, trabalham-se os aspectos da interação, ou seja, como as interfaces e todos os elementos de interação irão funcionar em conjunto e de maneira consistente. Não só se trabalha a interação das telas e elementos de interfaces uns com os outros, mas tem-se como objetivo a coerência entre o todo, englobando os componentes físicos e digitais. Muitas questões de usabilidade são tratadas nessa disciplina, como por exemplo a compatibilidade entre a expectativa do usuário sobre como o sistema funciona; a consistência e a padronização de elementos e sequências para contextos de interação semelhantes; o controle do usuário no processamento do sistema e interrupção do mesmo; entre outras.
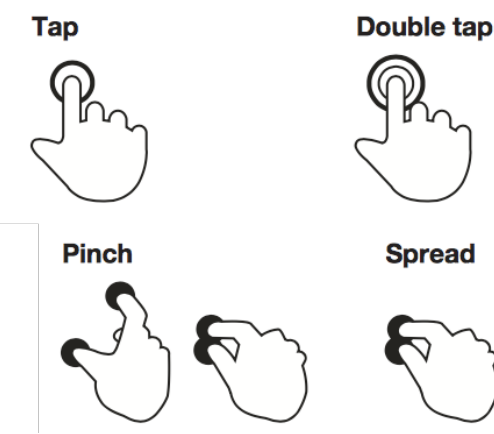

Drag

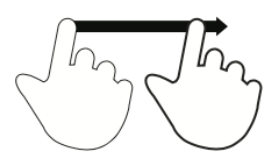

Press

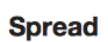

Spread
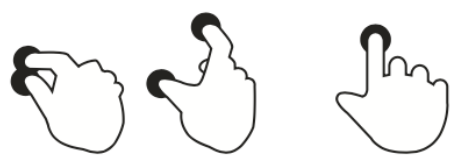

Flick

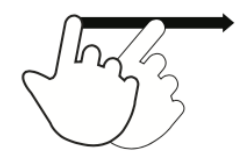

Press and tap

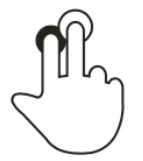

Figura 6: Essas figuras representam alguns dos gestos possíveis na interação com telas sensíveis ao toquede smartphones e tablets. É papel do designer de interação atribuir os gestos aos elementos de interação de uma interface. Fonte: https://www.lukew.com/ff/entry.asp?1071

\section{Design de Informação}

No design de informação o foco de trabalho passa a ser a informação que está sendo tratada na interação e é, obviamente, coordenada com a concepção dos elementos de interface e de interação que serão apresentados para o usuário. Questões de agrupamento e priorização da informação, qualidade e objetividade das informações, assim como a distribuição do conteúdo informacional entre telas ou outros suportes para evitar a sobrecarga mental do usuário são, também, tópicos fundamentais para a experiência do usuário na interação.

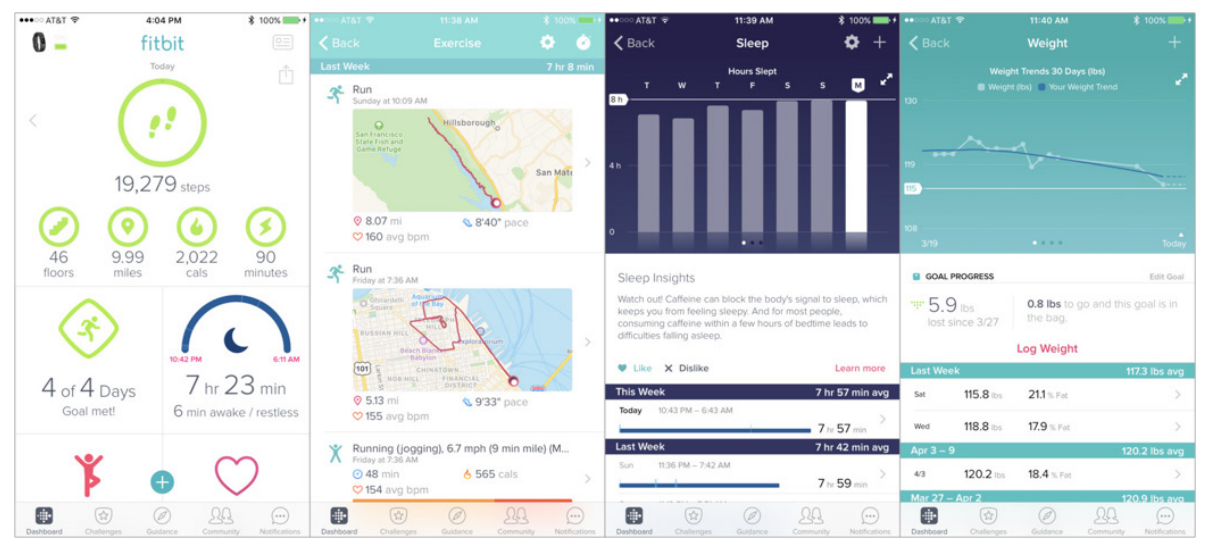

Figura 7: Neste exemplo, o aplicativo Fitbit expõe claramente o trabalho de Design de Informação - as formas de apresentação da informação (gráficos e mapas, por exemplo) são condizentes com os dados que precisam ser passados para os usuários. Fonte: https://itunes.apple.com/us/app/fitbit/id462638897?mt=8 


\section{Design de Serviço}

Como a experiência do usuário está, também, associada à relação do usuário com a empresa/instituição provedora do produto e ele não é uma parte isolada de um sistema, o design de [ou do] serviço deve ser adicionalmente trabalhado para a garantia da boa experiência com o produto. $\mathrm{O}$ design de serviço trabalha todas as ferramentas, métodos de relacionamento e pontos de contato do usuário com os sistemas relacionados ao produto. Da mesma forma que o design de interação trabalha o conjunto das partes do produto (interface/telas, elementos de interação, botões físicos, etc.), o design de serviço busca trabalhar com o relacionamento dos sistemas interligados ao produto que está sendo desenvolvido, também de forma consistente. Do ponto de vista do produto, se este é o sistema-alvo, o serviço é o alinhamento de todos os outros sistemas, construídos de forma coerente, de seu supra sistema.

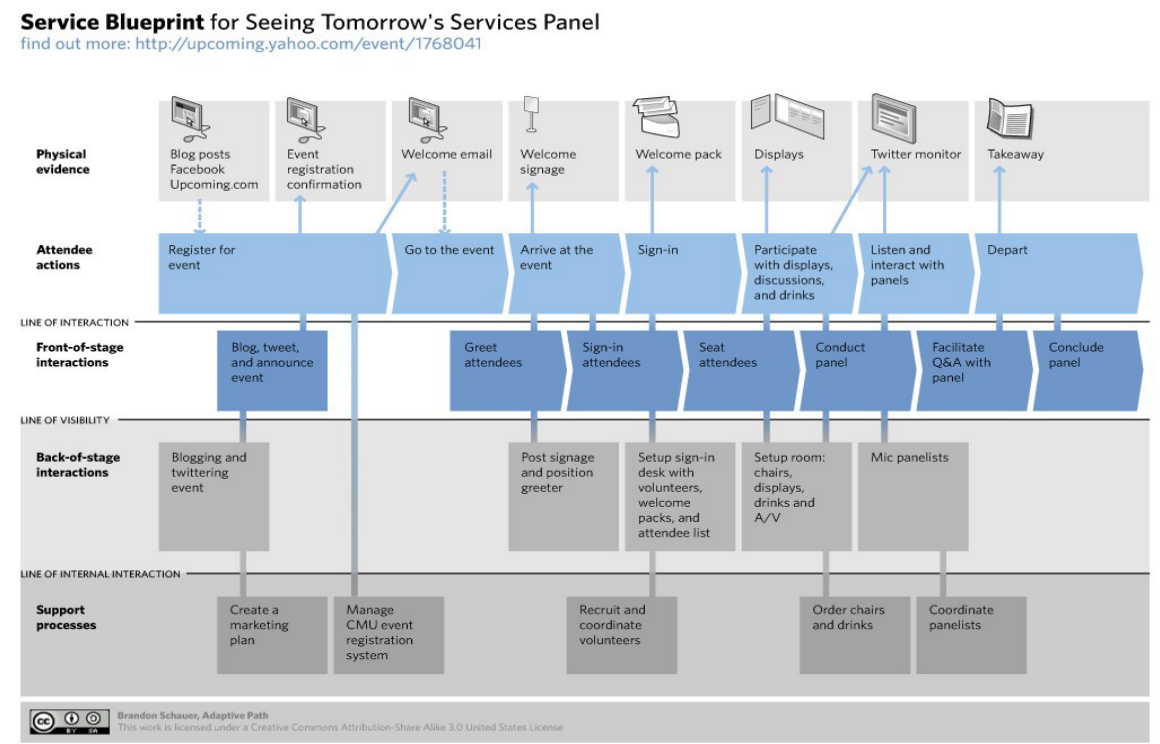

Figura 8: O Blueprint de serviço é um exemplo de uma síntese do que é trabalhado no Design de Serviço. Neste exemplo, são apresentadas as evidências físicas do serviço, as ações do usuário, as interações entre o usuário e o sistema, e todos os outros pontos de contato entre o usuário e o sistema. Fonte: https://www.interactiondesign.org/literature/article/service-blueprints-communicating-the-design-of-services

\section{Arquitetura de Informação}

A arquitetura de informação já diz respeito à organização e estruturação das informações do produto (e seus sistemas correlacionados) com o objetivo de atender as expectativas e necessidades do usuário, de forma compreensível. Em geral, os produtos ou sistemas interativos digitais vêm sobrecarregados de informação que precisam, além de estarem bem-dispostos e claros na interface (trabalhados no design de informação), ter suas informações organizadas e estruturadas de tal forma, que a navegação nas várias interfaces seja fluida para o usuário e que ele consiga recuperar facilmente uma informação. Neste sentido, a categorização do conteúdo informacional, distribuído de forma clara em menus e submenus, por exemplo, e a rotulação adequada dos grupos e subgrupos, passam a fazer parte da boa experiência. Se toda a arquitetura de informação não for trabalhada de maneira compatível com as expectativas do usuário, há uma grande chance de o produto não ser bem-sucedido e a experiência com ele será catastrófica. 


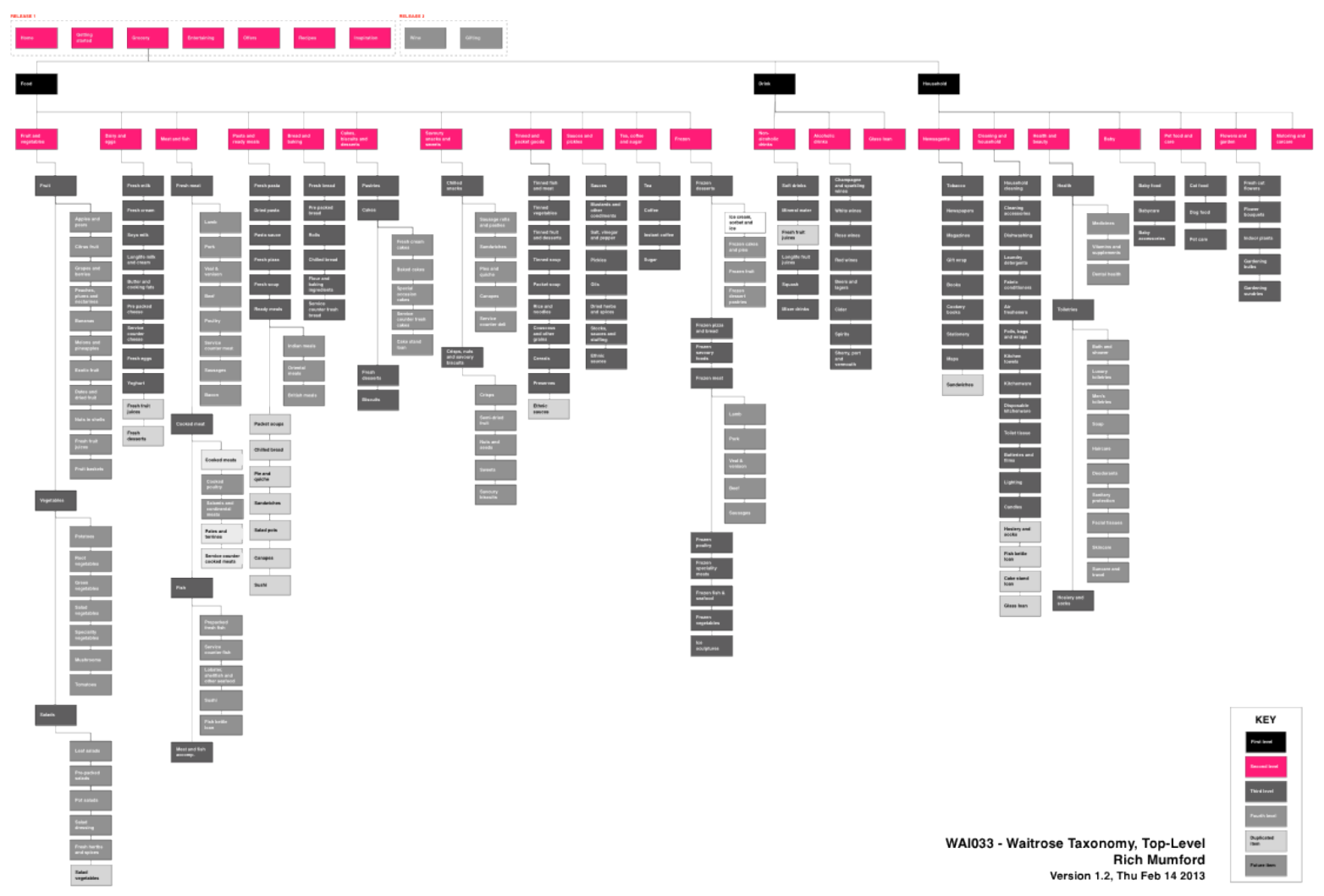

Figura 9: Exemplo de uma hierarquia de um website, onde são especificados todos os agrupamentos, rótulos e fluxo de navegação, etc., definidos no trabalho de Arquitetura de Informação. Fonte: http://www.human-thinking.co.uk/what-we-do/information-architecture/

Buley (2013) ainda acrescenta outras duas disciplinas, não necessariamente ligadas ao Design, que devem ser trabalhadas no projeto de um produto e que podem afetar na experiência do usuário: a pesquisa do usuário e a estratégia de conteúdo (ou copywriting).

\section{Pesquisa do usuário (user research)}

A pesquisa do usuário é, numa abordagem de projeto centrado no humano, parte fundamental para se chegar a um produto que possa levar a uma boa experiência. A partir de uma pesquisa com usuários é que se consegue descobrir quais são as suas reais necessidades e comportamentos. Entretanto, essa pesquisa deve ser feita de modo organizado e estruturado, a fim de que se obtenham dados e informações relevantes e que possam ser traduzidos em insumos para o projeto. Não adianta perguntar para o usuário o que ele quer (clássica frase de Steve Jobs sobre os consumidores de seus produtos), pois muitas vezes ele não vai conseguir dizer, mas é preciso entender quais são as suas necessidades e como ele faz para alcançar seus objetivos, e quais são os meios e/ou "gambiarras" que ele faz alcançá-los. Muitas vezes, a observação, a análise e a avaliação de comportamentos e atitudes são suficientes para se chegar a insights essenciais para o projeto e desenvolver soluções que promovam uma excelente experiência de uso.

\section{Estratégia de Conteúdo (ou copywrit- ing)}

Quando se trabalha com muito conteúdo informacional, não só as questões de apresentação da informação e organização da mesma precisam ser trabalhadas. Que conteúdo será exposto e qual é o seu papel nos diversos momentos de interação é parte estratégica do produto na experiência do usuário. Diversos fatores como linguagem, tipo de mensagem, tom e voz são fatores extremamente 
importantes para que a experiência seja consistente e única. Além de que, é preciso entender os diversos meios e contextos em que interação irá ocorrer para que se proponha o conteúdo, no momento certo e na hora certa. Por exemplo, que conteúdo de informação será fornecido de um mesmo serviço quando o usuário estiver num website em um desktop, no smartphone ou na pequena tela de um smartwatch? Os meios e os contextos podem ser e são diferentes, cabe ao projeto especificar a melhor maneira de formulação do conteúdo.

A empresa alemã Envis Precisely 3 elaborou um cartaz (figura 10) bastante interessante sobre as disciplinas de UX, baseado na publicação de Saffer (2009) em que o foco é o design de interação. O gráfico apresenta as relações das disciplinas e suas proporções na experiência do usuário de forma bastante pertinente em teoria, mas não necessariamente reflete a forma como o UX é trabalhado no mercado (FARREL e NIELSEN, 2014), uma vez que o termo UX é associado basicamente ao design de interface, de interação, arquitetura de informação e pesquisa do usuário. Muitas outras disciplinas são enumeradas no gráfico além das já mencionadas anteriormente, mas acredita-se que as que foram descritas são as que mais interferem no papel do designer.
3 http://envis-precisely. comepequenas ou grandes resoluções).

\section{The Disciplines of \\ User Experience Design}

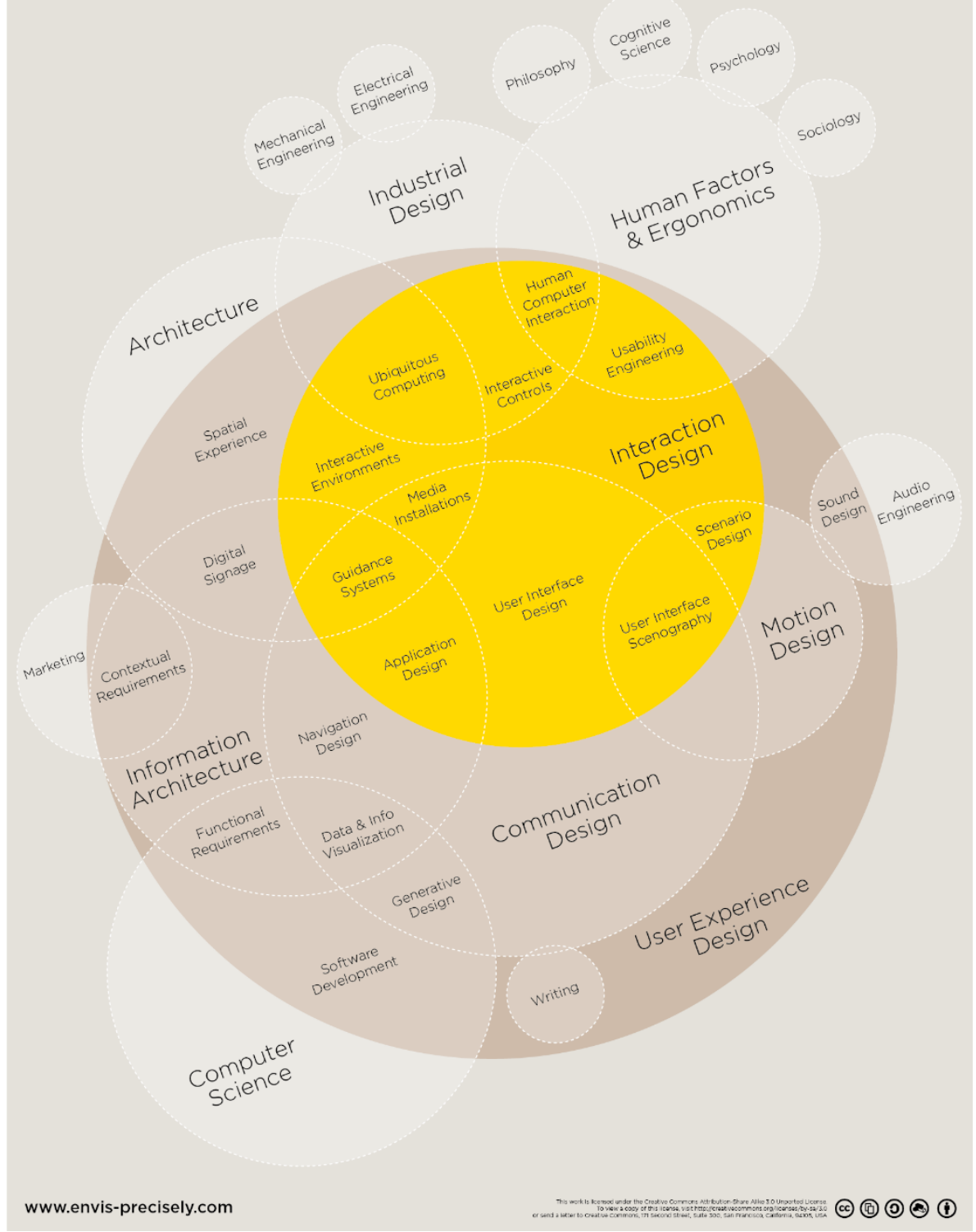

Figura 10: Disciplinas do UX Design. Fonte: https://github.com/envisprecisely/disciplines-of-ux 
Em síntese, são muitas as questões que precisam ser atendidas quando se planeja a trabalhar para a experiência do usuário. No entanto, segundo Buley (2013), a maioria das equipes de UX, formadas por poucas pessoas (e as vezes por uma pessoa só!), assume todas as responsabilidades das disciplinas apresentadas acima, em cargos intitulados "User Experience Designer" ou "User Experience Researcher", neste último caso quando o foco é um pouco mais voltado para a pesquisa do usuário. Além disso, estes profissionais atuam em variados processos de desenvolvimento de produto, com diversas abordagens e metodologias de projeto, como: design centrado no usuário/humano, design thinking, ágeis, Scrum, Lean Startup, Lean UX, Sprint e quantas outras forem surgindo.

Assim sendo, questiona-se: Quem são esses profissionais? Qual é a sua formação? Como obteve experiência em todas essas áreas?

Buley (2013) coloca que a maioria dos que trabalham com UX vem, primordialmente, de áreas com background de Ergonomia/Fatores Humanos e Usabilidade, o que faz com que as pessoas relacionem bastante o design de UX com o design de interface, mas, também, muitos vêm de outras áreas - com background em pesquisa, tecnologia e comunicação. Uma vez que a experiência do usuário lida com a comunicação tanto visual quanto textual, é razoável que profissionais com experiência em Design Gráfico e Jornalismo/Publicidade estejam trabalhando com UX. Da mesma forma que antigos desenvolvedores de softwares, web designers, webmasters e engenheiros passem agora a trabalhar com UX nas questões da tecnologia. Por fim, como é fundamental conhecer a fundo os comportamentos, atitudes, desejos e necessidades do usuário em UX, profissionais oriundos da Sociologia, Antropologia e Psicologia também fazem parte das equipes que trabalham para a experiência do usuário.

4 User Experience Professional Association organização internacional de profissionais que trabalham com UX com membros em 60 países - http://uxpa. orgcomepequenas ou grandes resoluções). sos de desenvolvimento do projeto são os métodos e técnicas utilizados para alcançar os objetivos da abordagem, o envolvimento do usuário no processo, tempo e orçamento. $\mathrm{O}$ investimento nesse tipo de abordagem vai depender da filosofia e maturidade da empresa, em relação ao foco que se quer dar para um projeto voltado para garantir uma boa experiência do usuário.

A ISO 9241-210 (2010) especifica os benefícios de se utilizar uma abordagem de projeto centrado no usuário e enumera uma série de princípios que devem ser seguidos, para que sua aplicação seja efetiva, tais como: 1) é necessário o entendimento explícito dos usuários, das tarefas, e dos ambientes de interação; 2) os usuários devem estar envolvidos em todo o processo de desenvolvimento do projeto; 3) o projeto deve ser conduzido e refinado através de avaliações com foco no usuário; 4) o processo deve ser iterativo (que permite as avaliações e o refinamento das soluções); 5) deve-se abordar toda a experiência do usuário (em todos os pontos de contato do usuário com o produto/serviço); e 6) a equipe de projeto deve incluir competências e perspectivas multidisciplinares (de forma a permitir que muitos aspectos da experiência sejam trabalhados).

A abordagem do Design Centrado no Usuário conta com, basicamente, quatro grandes etapas/atividades (figura 11): compressão e especificação do contexto de uso, a especificação dos requisitos dos usuários, a criação de soluções de design para esses requisitos e avaliação de soluções [protótipos] (ISO, 2010).

Num primeiro momento do projeto, o que se pretende é compreender quem são os usuários, quais são seus objetivos, como eles os alcançam (análise da tarefa), onde realizam suas tarefas e sob que condições. Com esses dados levantados, através de pesquisas de campo, é possível especificar o perfil dos usuários e o contexto de uso. Assim, são especificados, normalmente, a jornada do usuário, os cenários de uso, as personas e os objetivos dos usuários que precisam ser atendidos no projeto. A partir de então é que se parte para a criação de soluções para atender os requisitos especificados, que começa com um trabalho de arquitetura de informação, definição do fluxo de tarefas, o design (visual) das interfaces, a especificação de guias de estilo e padrões, até a confecção de protótipos. Paralelamente, as ideias e os protótipos que vão surgindo vão sendo validados e refinados com os usuários através de avaliações como teste de arquitetura de informação e testes de usabilidade. Todo esse processo descrito é trabalhado de forma iterativa até a solução final atenda a todos os requisitos especificados. 


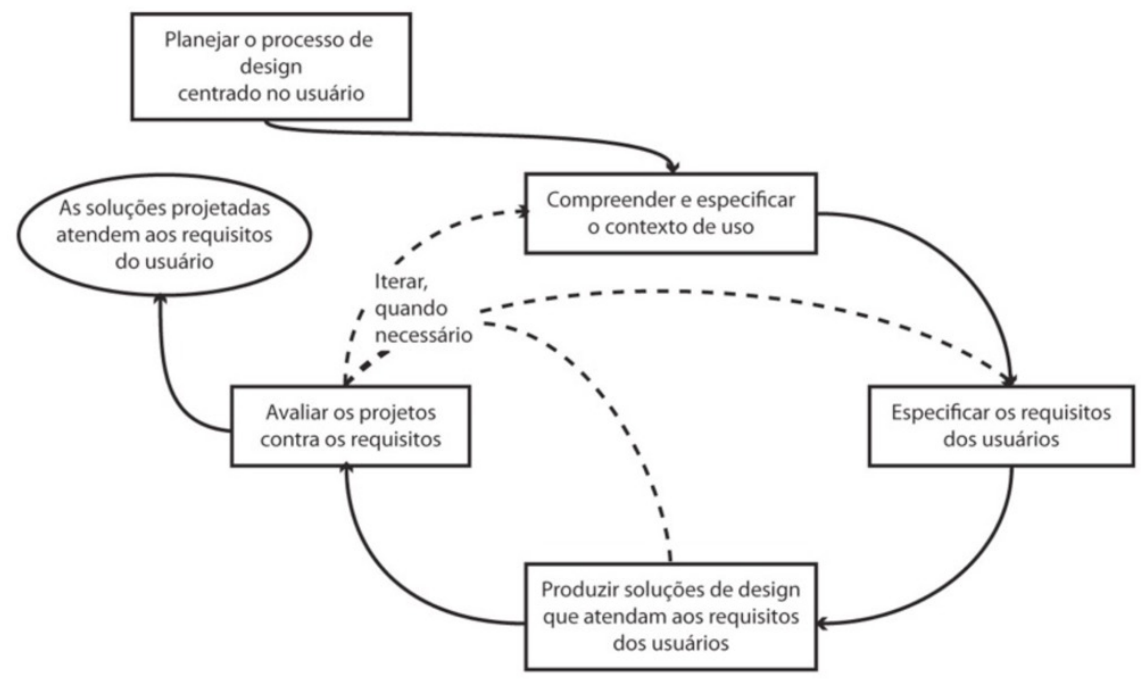

Figura 11: Etapas/ atividades da abordagem do Design Centrado no Usuário. Fonte: ISO 9241-210 (2010)

Com o objetivo de compreender melhor a atuação profissional na área de UX, Farrell e Nielsen (2014) realizaram um levantamento a respeito das carreiras em UX, com mais de 960 profissionais, através de um questionário distribuído internacionalmente. Entretanto, apesar dessa distribuição, a maior parte dos respondentes (70\%) moravam em países norteamericanos, Estados Unidos e Canadá, e Reino Unido e Austrália - países com maturidade em UX mais avançada em relação ao resto do mundo.

Como principais achados, os autores concluíram que há uma diversidade muito grande em termos de características do profissional de UX, tanto nas questões de formação, conhecimentos e experiência, quanto em que esse profissional trabalha e que tipo de interação ele trabalha para a experiência do usuário. Foi levantado que a maioria dos respondentes concentram a sua atuação em quatro tipos de plataformas: websites e web apps, aplicativos para dispositivos móveis, aplicativos de empresas e softwares tradicionais para desktop. Porém, os profissionais não necessariamente trabalham só com uma das plataformas, mas muitos trabalham com várias ao mesmo tempo - em média trabalham com cinco plataformas diferentes. De onde se conclui que não é uma carreira na qual se aprende uma determinada habilidade e continuará a trabalhar com ela até o final.

Quanto aos papéis desempenhados no trabalho de UX, os autores explicitam que os principais são em pesquisa do usuário, design de interação e arquitetura de informação (figura 12), sendo que um pouco menos da metade dos respondentes já atuou nos três papéis, o que mostra uma diversidade de conhecimentos e experiência bem grande. E, em relação às atividades desempenhadas no trabalho, como construção de wireframes ou condução de testes, por exemplo, a maioria respondeu executar mais de dezesseis atividades diferentes ao longo dos projetos. Não é à toa que os respondentes disseram estar em constante "modo de aprendizado".

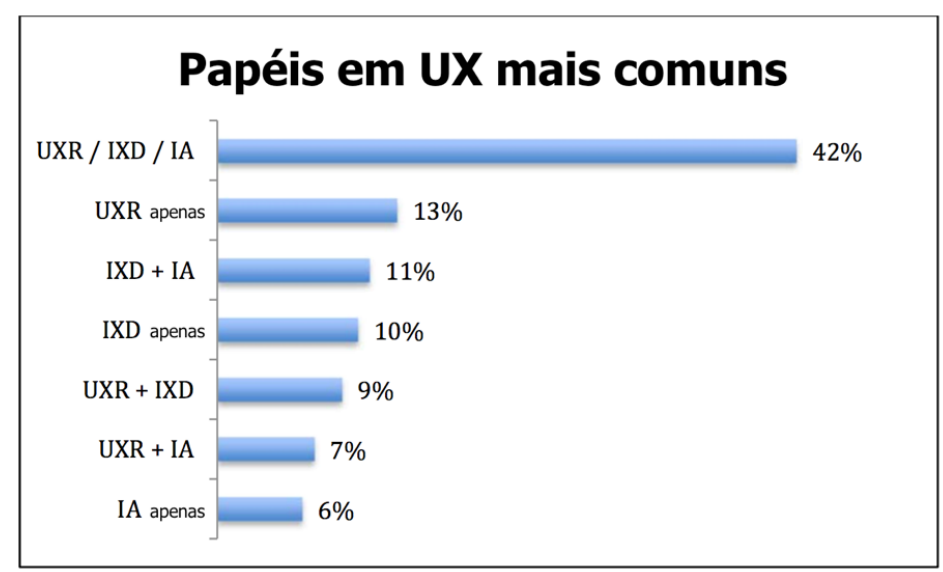

Figura 12:Papéis mais comuns desempenhados na área de UX. UXR - pesquisa em user experience; IXD design de interação; IA - arquitetura de informação. Fonte: Farrell e Nielsen (2013) [tradução da autora] 
De acordo com o levantamento, a formação dos profissionais também é bastante variada, mas a maioria (90\%) tem formação universitária, sendo Design, Psicologia e Comunicação as áreas mais comuns no bacharelado (figura 13). Entretanto, em relação aos níveis de escolaridade, mais da metade (52\%) tem mestrado, mas poucos têm doutorado (6\%). Os restantes são bacharéis ou têm outras formações.

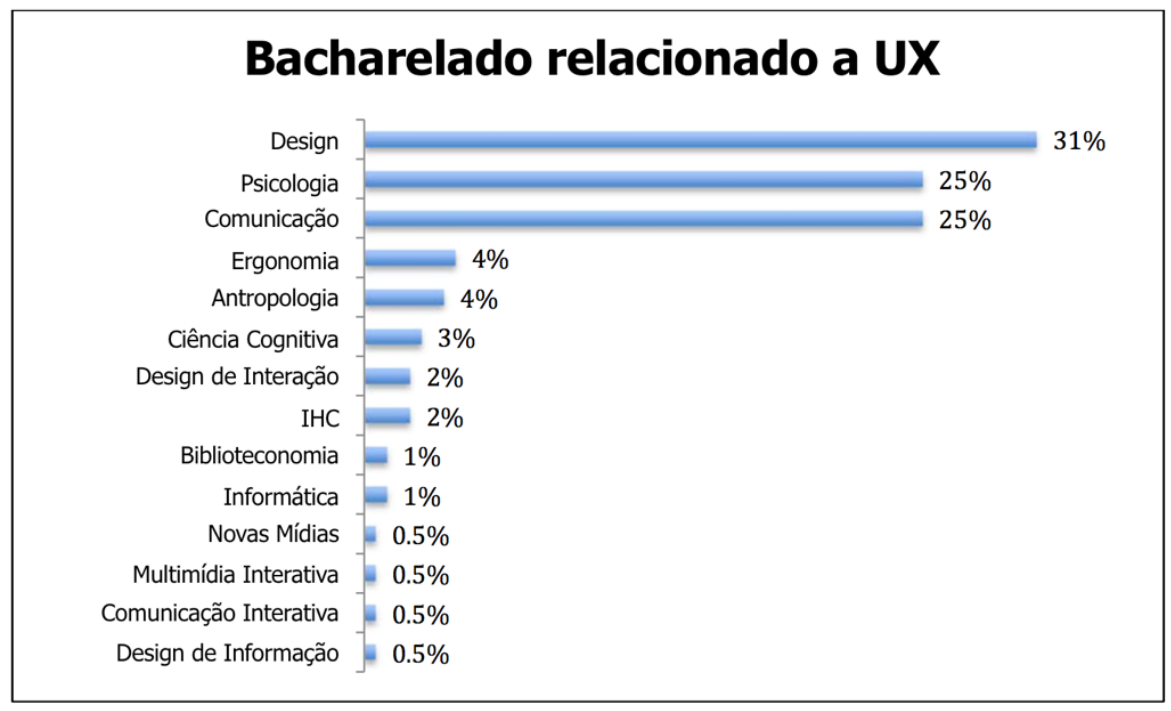

Figura 13: Graduações/Bacharelado relacionados a UX. Fonte: Farrell e Nielsen (2013) [tradução da autora]

As áreas de formação no mestrado também não seguem um padrão e são as mais diversas, mas a mais popular é a IHC (Interação Humano-Computador), o que foi considerado pelos autores como altamente especializado para a carreira. Outras áreas como Design de Informação, Ergonomia, Design Digital e Comunicação Técnica tiveram, também, certa relevância entre os entrevistados. A conclusão dos autores é a de que é, claramente, possível ter uma carreira em UX sem ter tido uma formação na área e que não necessariamente precisa se ter uma graduação universitária (lembrando que se trata de uma maioria de profissionais de países desenvolvidos com boa formação de base).

Dentre os assuntos/tópicos citados pelos respondentes, os considerados como principais e úteis para a atuação na área de UX foram: web design, redação/texto, programação, psicologia, design e métodos de pesquisa. É interessante observar que 20\% dos respondentes disseram que trabalham tanto com UX quanto com programação de software e outros muitos disseram que gostariam de ter esse conhecimento. Os autores ainda colocam que
HTML/CSS são conhecimentos essenciais para trabalhar com UX, segundo os respondentes. Isso parece mostrar uma convergência entre áreas, como Design e Engenharia de Software, que, antigamente, eram complementares.

Não é de se espantar que a maioria dos cargos é, hoje, no mercado de UX, ocupada por profissionais generalistas (figura 14) e com variado leque de conhecimentos, conforme a UXPA apresenta em um levantamento mais recente realizado com uma amostra de profissionais semelhante à do estudo anterior e com foco salário dos profissionais da área (UXPA, 2017). Com tantas evoluções de tecnologia e na área de interação humano computador, será que mesmo os princípios de usabilidade são compreendidos e bem aplicados? Será possível que essa formação generalista dê conta de um bom projeto para uma boa experiência do usuário? 


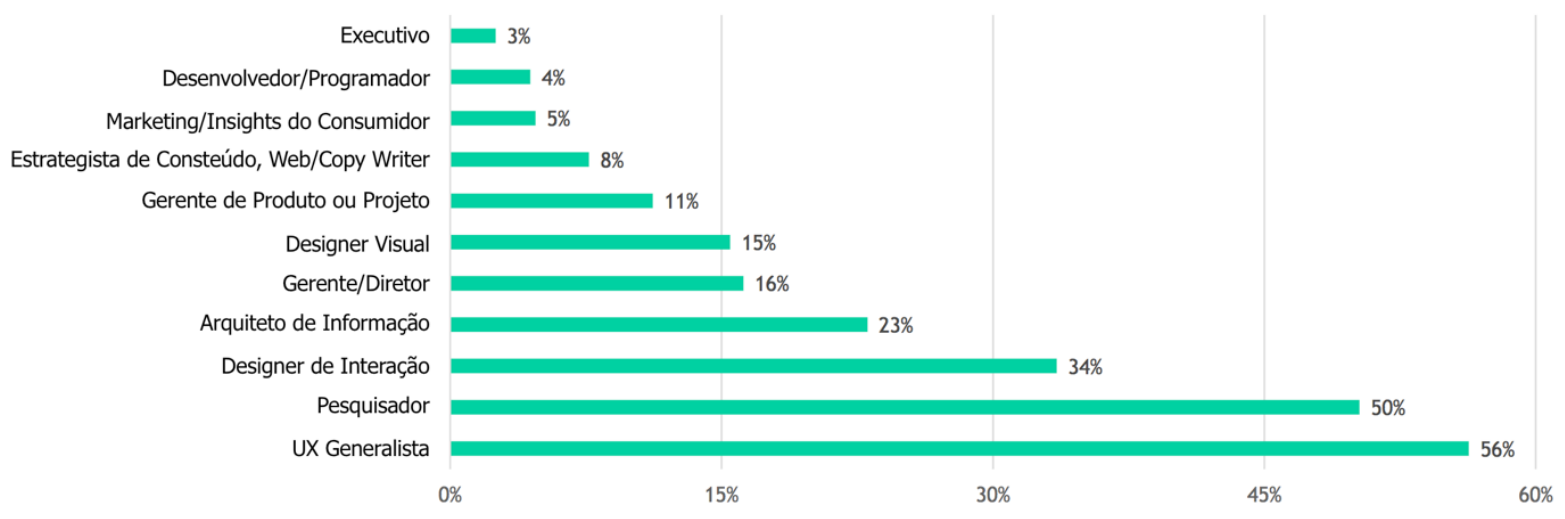

Figura 14: Cargos ocupados na área de UX. Fonte: UXPA (2017) [traduação da autora]

\section{Considerações Finais}

Como é possível observar em pesquisas, em blogs e fóruns que discutem sobre a experiência do usuário, o conceito de UX ainda é confuso e as pessoas têm muita dificuldade de delimitar a área, mesmo com quase três décadas de existência. Ainda se confunde muito o que é Usabilidade e o que é User Experience. Considera-se o UX como algo a mais em relação a Usabilidade, mas, também, não se consegue trabalhar muito além dela, pois é difícil trabalhar para uma experiência que é individual e que está relacionada a uma quantidade variáveis que, muitas vezes, é impossível de serem controladas.

Nesse contexto, quando se trata de mercado de trabalho, se vê uma demanda de exigências, conhecimentos e competências para o profissional que algumas vezes não condiz com os fundamentos básicos da formação do profissional. Por exemplo, como atribuir a um mesmo profissional a tarefa de fazer a pesquisa com o usuário, para entender seus comportamentos, e a tarefa de programação do sistema e seu desenvolvimento lógico. Trabalhar com humanos é bem diferente que trabalhar com máquinas, as "empatias" são diferentes e podem ser opostas. Mas, felizmente, esses são casos extremos que se tem no mercado e ocorrem em pequenas empresas que ainda não se estruturaram de forma a atingir uma maturidade na área de UX, onde poucas pessoas precisam fazer o trabalho de muitas.

Outro fenômeno que pode ser observado é a variedade de formação entre os profissionais que hoje trabalham para as questões de experiência do usuário. Da mesma forma que é difícil delimitar a área de UX é difícil saber qual é a formação profissional mais adequada para o trabalho. $\mathrm{O}$ que $\mathrm{o}$ mercado deve buscar é, na verdade, um profissional mais adequado ao ponto de vista que se quer dar na experiência. Se é compreendido que a ênfase na experiência tem que ser o conhecimento do comportamento do usuário, busca-se alguém com competência em pesquisa, mas se é compreendido que a ênfase deva ser dada no design da interface, contrata-se um profissional experiente nesse assunto. Acredita-se que deva ser difícil para uma empresa contratar um profissional de UX quando não se tem o conhecimento pleno da área e quando não se tem claro o que é que se quer atingir.

Apesar de todas as dificuldades, o UX é uma área em ascensão e muito visada pelos profissionais atualmente, tanto é que a oferta de cursos de extensão nas diversas disciplinas que envolvem UX é bem extensa, no mercado internacional e no Brasil. Mas questiona-se, por que tantos cursos de extensão se a maior parte das disciplinas são relacionadas a Design? Por que tais conhecimentos não são adquiridos em cursos de graduação em Design? É possível ter uma graduação em Design que cubra a formação de um profissional com todos os conhecimentos necessários para trabalhar com UX?

Quando se trabalha com tecnologias que vão evoluindo e novos tipos de interação que vão surgindo, é bem complicado prever o futuro e prever como será o trabalho do designer com essas novas interações. Entretanto, é preciso ter em mente que a parte mais importante da interação humano-computador é o "humano" e esse não evolui e não muda da mesma forma como o computador. Designers precisam focar seus esforços na compreensão do comportamento humano e sua relação com todo o ecossistema envolvido e não apenas na interface em si que estão projetando. O UX designer bem-sucedido é aquele que tem uma visão holística da experiência do usuário. Trabalhar com esta visão fará do designer uma das peças fundamentais da estratégia de negócio de uma empresa. 


\section{Referência Bibliográficas}

BRANGIER, E.; BARCENILLA, J. Concevoir un produit facile à utiliser. Editions d'Organisation, 2003.

BULEY, L. The user experience team of one: a research and design survival guide. Rosenfeld Media, 2013.

FARRELL, S.; NIELSEN, J. User Experience Careers. Disponível em: <https://www.nngroup. com/reports/user-experience-careers/> . Acesso em: 3 jan. 2017.

HARTSON, R.; PYLA, P. The ux book: process and guidelines for ensuring a quality user experience. Morgan Kaufmann, 2012.

INTERNATIONAL ORGANIZATION FOR STANDARDIZATION. ISO 9241-11: Ergonomic requirements for office work with visual display terminals (VDTs) - part 11: guidance on usability, 1998.

INTERNATIONAL ORGANIZATION FOR STANDARDIZATION. ISO 9241-210: Ergonomics of human-system interaction - Human-centred design for interactive, 2010.

JORDAN, P. W. Designing pleasurable products: an introduction to the new human factors. CRC Press Taylor \& Francis, 2002.

KUNIAVSKY, M. Smart things: ubiquitous computing user experience design: ubiquitous computing user experience design. Burlington: Morgan Kaufmann Publisher, 2010.

NIELSEN, J.; MACK, R. L. Usability inspection methods. New York: Wiley, 1994.

NORMAN, D. A. The psychology of everyday things. Basic Books Inc., 1988.

NORMAN, D. A. The design of everyday things. Basic Books, 2013.

SAFFER, D. Designing for interaction: creating innovative applications and devices. Berkley: New Riders, 2010.

SHNEIDERMAN, B. Designing the user interface: strategies for effective humancomputer interaction. 1st. ed. Reading: Addison-Wesley Publ. Co., 1987.

SHNEIDERMAN, B. Software psychology: human factors in computer and information systems. Winthrop Publishers, 1980.

UXPA. 2016 UX Salary Survey. Disponível em: < https://uxpa.org/system/files/public/ UXPASalarySurvey2016_final.pdf>. Acesso em: 20 mai. 2017. 